\title{
Chest compression-related fatal internal mammary artery injuries manifesting after venoarterial extracorporeal membrane oxygenation: a case series
}

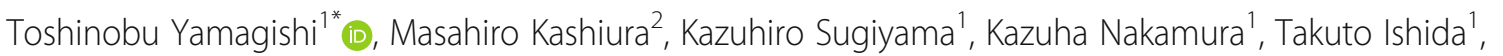
Takahiro Yukawa' ${ }^{1}$ Kazuki Miyazaki ${ }^{1}$, Takahiro Tanabe ${ }^{1}$ and Yuichi Hamabe ${ }^{1}$

\begin{abstract}
Background: Cardiopulmonary resuscitation-related bleeding, especially internal mammary artery injuries, can become life-threatening complications after initiating venoarterial extracorporeal membrane oxygenation owing to the frequent involvement of concomitant anticoagulant treatment, antiplatelet treatment, targeted temperature management, and bleeding coagulopathy. We report the cases of five patients who experienced this complication and discuss their management.

Case presentation: We retrospectively evaluated five patients with cardiopulmonary resuscitation-related internal mammary artery injuries who were treated between February 2011 and February 2016 at our institution. All five patients were Asian men, aged 56 to 68-years old, who had received concomitant intravenously administered unfractionated heparin (3000 units) with antiplatelet therapy. Four patients received targeted temperature management. The injuries and hematomas were detected using contrast-enhanced computed tomography in all cases. Three patients were treated using transcatheter arterial embolization within 6 hours following cardiopulmonary arrest, and two were resuscitated and received appropriate treatment following early recognition of their injuries. Two patients died of hemorrhagic shock with delayed intervention. Four of the five patients had excessively prolonged activated partial thromboplastin times before their interventions.

Conclusions: Computed tomography should be performed as soon as possible after the return of spontaneous circulation to identify injuries and consider appropriate treatments for patients who have experienced cardiac arrest. Delayed bleeding may develop after treating hypovolemic shock and relieving arterial spasms; therefore, transcatheter arterial embolization should be performed aggressively to prevent delayed bleeding even in the absence of extravasation. This approach may be superior to thoracotomy because it is less invasive, causes less bleeding, and can selectively stop arterial bleeding sooner. A 3000-unit intravenous bolus of unfractionated heparin may be redundant; heparin-free extracorporeal cardiopulmonary resuscitation may be a more appropriate alternative. Unfractionated heparin treatment can commence after the bleeding has stopped.
\end{abstract}

Keywords: Extracorporeal membrane oxygenation, Cardiopulmonary resuscitation, Mammary arteries, Hemorrhagic shock, Therapeutic embolization, Heparin, Platelet aggregation inhibitors, Induced hypothermia

\footnotetext{
*Correspondence: t_yamagishi0211@yahoo.co.jp

'Tertiary Emergency Medical Center, Tokyo Metropolitan Bokutoh Hospital,

4-23-15 Kotobashi, Sumida-ku, Tokyo 130-8575, Japan

Full list of author information is available at the end of the article
} 


\section{Background}

Chest compressions for cardiopulmonary resuscitation (CPR) were emphasized in the 2010 American Heart Association CPR guidelines [1]. However, CPR-related bleeding complications are not uncommon [2-4], and CPR-related fractures have been observed more frequently since 2010 [5, 6]. Furthermore, CPR-related bleeding, particularly internal mammary artery (IMA) injuries, can become life-threatening in patients who undergo extracorporeal cardiopulmonary resuscitation (ECPR) because concomitant anticoagulant treatment [7], antiplatelet treatment, targeted temperature management [8], and bleeding coagulopathy [9] are often involved. We investigated five patients with CPR-related IMA injuries that occurred after they had undergone venoarterial extracorporeal membrane oxygenation (VA-ECMO).

\section{Case presentations}

We retrospectively evaluated the medical records of patients with cardiac arrest who underwent VA-ECMO between February 2011 and February 2016 at our institution. Of the 129 patients identified, five experienced CPR-related IMA injuries. Four of these patients underwent ECPR and one underwent VA-ECMO for cardiogenic shock after the return of spontaneous circulation (ROSC). All five patients were Asian men who had received 3000 units of intravenously administered unfractionated heparin with concomitant antiplatelet therapy for suspected acute coronary syndrome. Four of the five patients underwent targeted temperature management (the exception being Patient 3). Contrastenhanced computed tomography $(\mathrm{CT})$ revealed CPRrelated chest bleeding complications in all cases, for example, IMA injuries, intercostal artery (ICA) injuries, mediastinum hematoma, and hemothorax.

\section{Case 1}

A 65-year-old Asian man had a history of myocardial infarction and atrial fibrillation, and was receiving dual antiplatelet and warfarin treatment. After collapsing at a concert, he received immediate bystander CPR as well as six automated external defibrillator shocks before the emergency medical service (EMS) arrived; he was then transported to our hospital. His rhythm was asystole at the time of admission, and VA-ECMO commenced 45 minutes after his cardiac arrest because conventional CPR did not result in ROSC. Contrast-enhanced CT after starting VA-ECMO revealed bilateral multiple rib fractures, a sternum fracture, and right pleural effusion without contrast extravasation (Fig. 1a). Transcatheter arterial embolization (TAE) was not indicated; coronary angiography (CAG) was performed for suspected cardiogenic cardiac arrest based on the prehospital shockable rhythm. His left circumflex artery was completely occluded, and percutaneous coronary intervention (PCI) was attempted but failed because of strong calcification. Repeat contrast-enhanced CT was performed because of unstable blood flow during the VA-ECMO, and our patient exhibited a gradual decrease in his hemoglobin (Hb) levels from $10.8 \mathrm{~g} / \mathrm{dL}$ at admission to $8.4 \mathrm{~g} / \mathrm{dL} 2$ hours later. CT revealed contrast extravasation at his mediastinum and right anterior chest wall, with increases in the sizes of the hematomas (Fig. 1b). TAE was performed for his right IMA and right ICA using nbutyl cyanoacrylate (NBCA) 560 minutes after his cardiac arrest. His activated partial thromboplastin time was $>130$ seconds before TAE. He subsequently died 2 hours after TAE despite receiving 26 red blood cell units, 16 fresh frozen plasma units, and three packs of cryoprecipitate.

\section{Case 2}

A 68-year-old Asian man was transported to another hospital by the EMS because of chest pain. Ventricular fibrillation (VF) was noted on his arrival, and conventional CPR was performed immediately. He achieved ROSC after four defibrillation shocks, and was subsequently transferred to our hospital for post-cardiac arrest care. An intra-aortic balloon pump (IABP) was inserted at our hospital for cardiogenic shock, and CAG was also performed, revealing total occlusion of his left anterior descending artery. He was diagnosed as having acute myocardial infarction and underwent successful PCI. Chest radiography did not reveal any traumatic abnormalities (Fig. 2a), and his hemodynamics were maintained using IABP and a continuous infusion of noradrenalin. Minimal change was observed in his $\mathrm{Hb}$ levels (admission, $13.5 \mathrm{~g} / \mathrm{dL}$; 6 hours later, $13.3 \mathrm{~g} / \mathrm{dL}$ ). Two days after admission, he suddenly deteriorated, and VA-ECMO was initiated for suspected cardiogenic shock. However, his $\mathrm{Hb}$ level decreased to $5.3 \mathrm{~g} / \mathrm{dL}$, which indicated hemorrhagic shock. Ultrasonography and chest radiography revealed massive left pleural effusion (Fig. 2b), and a massive hemothorax was diagnosed after inserting a chest drainage tube. The blood flow from the drainage tube was $>200 \mathrm{~mL} /$ hour for several hours, and contrast-enhanced CT was performed to identify the source of the bleeding. Contrast extravasation was noted behind his left sixth rib, as well as hematoma at his mediastinum and hemothorax without rib fracture (Fig. 2c). Thoracotomy was performed to achieve hemostasis 48 hours after cardiac arrest. Although the bleeding appeared to originate from his left ICA, it was difficult to stop; therefore, an artery involved with the adjacent rib was also ligated. However, this procedure did not stop the bleeding from the left chest drain, and angiography at 8 hours after the thoracotomy revealed 

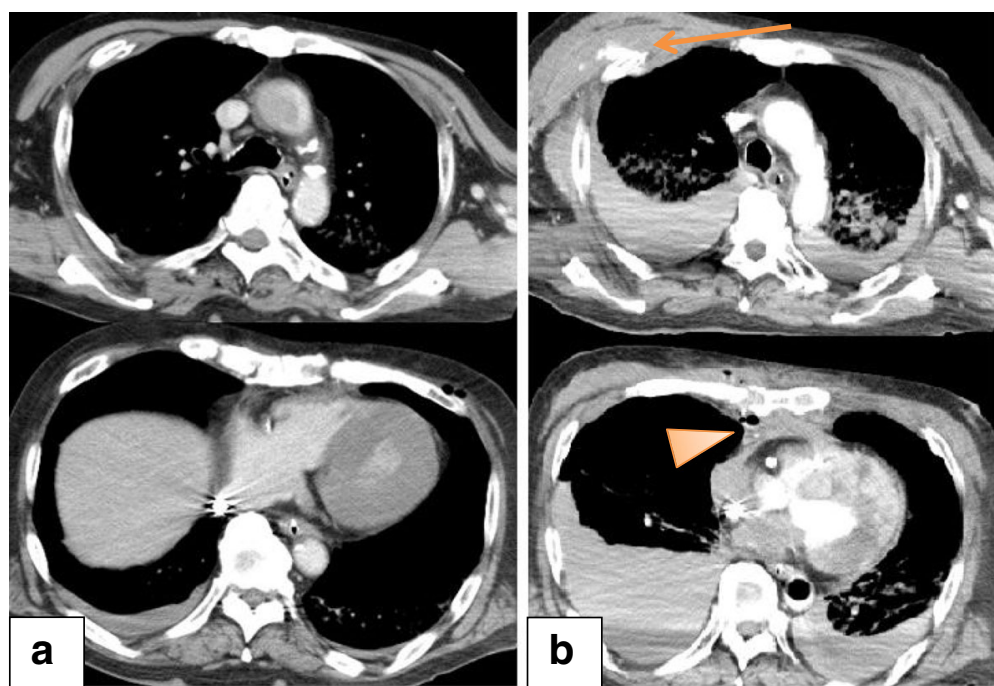

Fig. 1 Computed tomography findings from Patient 1. a Contrast-enhanced computed tomography after the extracorporeal cardiopulmonary resuscitation revealed bilateral multiple rib fractures, a sternum fracture, and right pleural effusion without contrast extravasation. b Repeat contrast-enhanced computed tomography after coronary angiography revealed contrast extravasation at the anterior chest wall (arrow) and mediastinum (arrowhead), with increases in the size of these hematomas

bleeding from his left IMA. TAE was performed using microcoils and gelatin sponge pledgets, but did not control the bleeding. He subsequently died because of hemorrhagic shock 8 hours after the TAE.

\section{Case 3}

A 56-year-old Asian man (an in-patient) had undergone an emergency graft implantation for a type A aortic dissection. On the eighth day post-surgery, he lost consciousness and experienced cardiac arrest that was witnessed by a surgeon in the general ward. He experienced refractory VF after conventional CPR, and VA-ECMO was started 28 minutes after the cardiac arrest. CAG revealed a thrombus between the aortic graft and the left main trunk of his coronary artery. Blood flow in his coronary artery improved after thrombus aspiration and
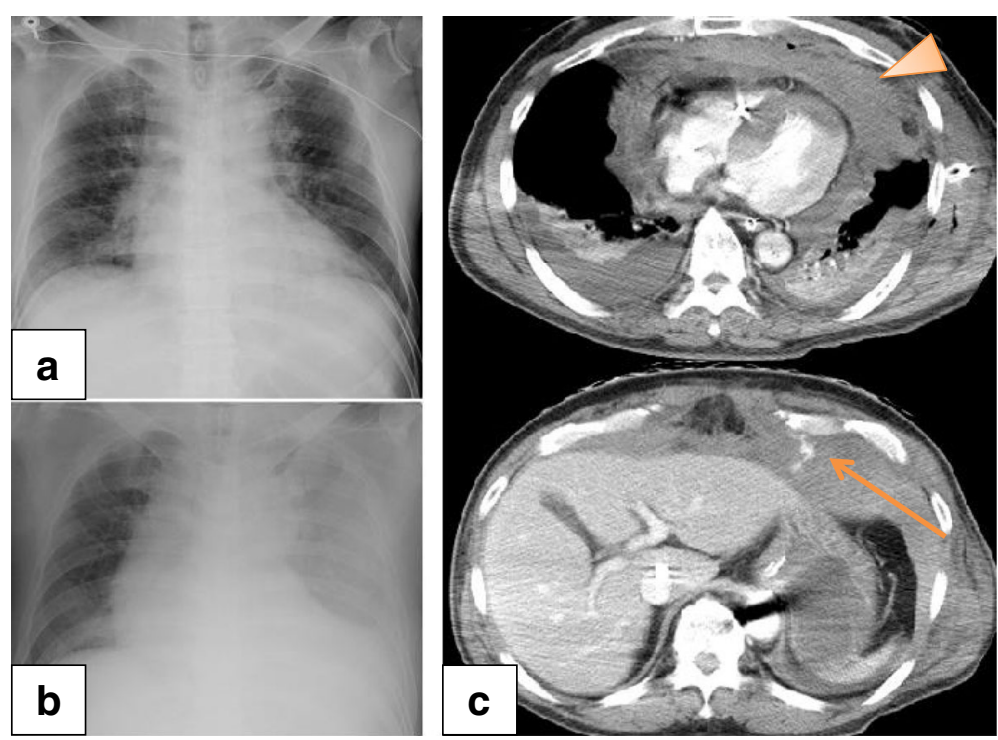

Fig. 2 Chest radiography and computed tomography findings from Patient 2. a Chest radiography at the time of admission did not reveal any traumatic abnormalities. $\mathbf{b}$ Chest radiography 3 days after the admission revealed decreased left lung permeability. $\mathbf{c}$ Contrast-enhanced computed tomography from after the insertion of a chest drainage tube revealed extravasation of the contrast agent behind the left sixth rib (arrow), a hematoma at the mediastinum (arrowhead), and chest cavities without any obvious rib fractures 
balloon angiography. Contrast-enhanced $\mathrm{CT}$ after the PCI revealed extravasation and a hematoma at the mediastinum (Fig. 3a). Angiography revealed that the extravasation was proximal to his left IMA (Fig. 3b). Although TAE was performed using NBCA at 313 minutes after his cardiac arrest, the spasm persisted and ECMO flow could not be maintained at that time. He died $41 \mathrm{mi}-$ nutes after the TAE.

\section{Case 4}

A 62-year-old Asian man was transported to our hospital by the EMS because of pulseless electrical activity after receiving bystander CPR. VF was documented at the admission, and VA-ECMO was started for refractory VF 55 minutes after his cardiac arrest. Contrastenhanced CT revealed a sternal fracture and a retrosternal hematoma with contrast extravasation (Fig. 4a). CAG was initially performed because the VA-ECMO flow was maintained and revealed $90 \%$ stenosis of his left main trunk. He was diagnosed as having acute myocardial infarction and underwent successful PCI. IABP was initiated to treat cardiogenic shock during the VA-ECMO. He exhibited a gradual decrease in his $\mathrm{Hb}$ levels: admission, $16.3 \mathrm{~g} / \mathrm{dL} ; 4$ hours later, $14.2 \mathrm{~g} /$ dL. Repeat contrast-enhanced CT was performed because of the hematoma and contrast extravasation, and revealed new contrast extravasation behind his right fifth costal cartilage and beside his sternum, as well as growing hematomas in the retrosternal space (Fig. 4b). Angiography revealed extravasations at his bilateral IMAs, and TAE was performed using NBCA at
327 minutes after his cardiac arrest (Fig. 4c). The TAE successfully decreased the IMA flow and the extravasations disappeared. The VA-ECMO and IABP were tapered on day 7 and day 11 post-admission, respectively. He was subsequently transferred to another hospital for rehabilitation on day 123 at which point his Glasgow-Pittsburgh cerebral performance category was 3 .

\section{Case 5}

A 62-year-old Asian man was transported to our hospital by the EMS because of VF after four defibrillation shocks. VA-ECMO was started for refractory VF at 40 minutes after his cardiac arrest. Contrast-enhanced CT before the CAG revealed right rib fractures, a sternum fracture, and a mediastinal hematoma with contrast extravasation (Fig. 5a). CAG did not reveal any coronary artery stenosis, and selective right IMA angiography subsequently identified the extravasation (Fig. 5b). Artery embolization was performed using gelatin sponge pledgets and microcoils at 181 minutes after his cardiac arrest, and IABP was started after the TAE. He was a heavy drinker and was diagnosed as having VF that was caused by hypomagnesemia (serum magnesium level of $1.7 \mathrm{mg} / \mathrm{dL}$ at admission) and hypokalemia (serum potassium level of $2.6 \mathrm{mmol} / \mathrm{L}$ at admission). The VA-ECMO and IABP were tapered on days 2 and 4 post-admission, respectively. After implantation of a cardiac defibrillator, he was transferred to another hospital for rehabilitation on day 88 , when he exhibited a cerebral performance category of 3 .

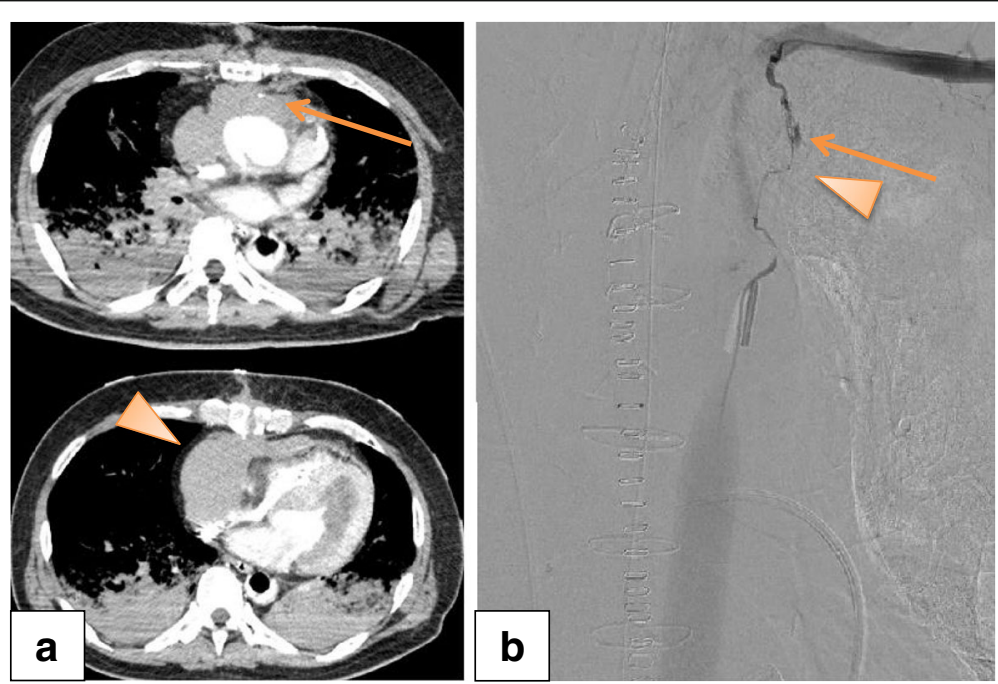

Fig. 3 Computed tomography and angiography findings from Patient 3. a Contrast-enhanced computed tomography after the percutaneous coronary intervention revealed contrast extravasation (arrow), a hematoma at the mediastinum (arrowhead), and compression of the right atrium and ventricle. b Angiography after the contrast-enhanced computed tomography revealed contrast extravasation proximal to the left internal mammary artery (arrow) with arterial spasm (arrowhead) 

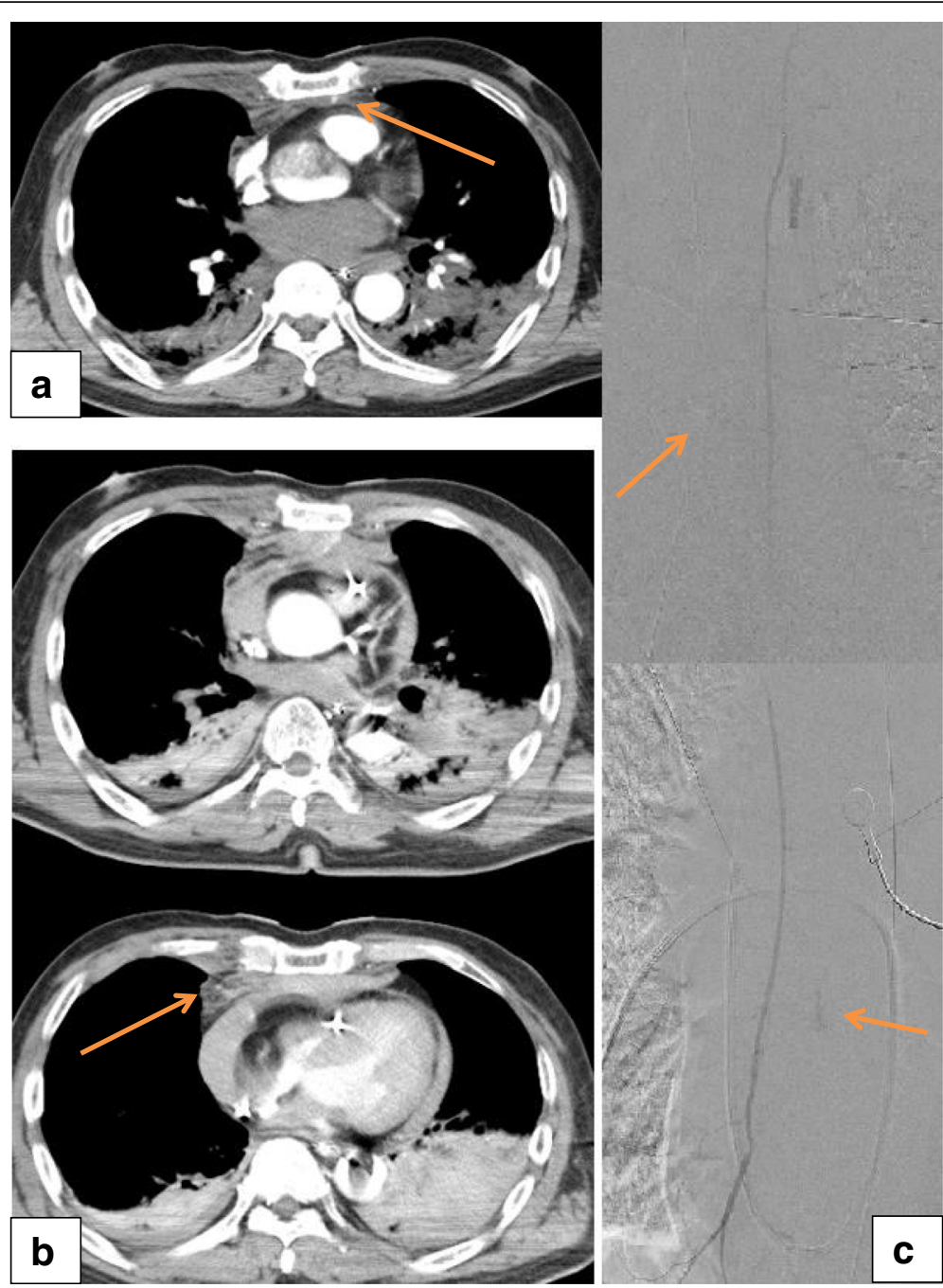

Fig. 4 Computed tomography and angiography findings from Patient 4. a Contrast-enhanced computed tomography before the coronary angiography revealed a sternal fracture and a retrosternal hematoma with contrast extravasation of contrast (arrow). b Repeat computed tomography after the percutaneous coronary intervention revealed new contrast extravasation behind the fifth costal cartilage and beside the sternum (arrow), as well as growing hematomas in the retrosternal space. c Angiography after the percutaneous coronary intervention revealed bilateral contrast extravasation at the bilateral internal mammary arteries (arrows)
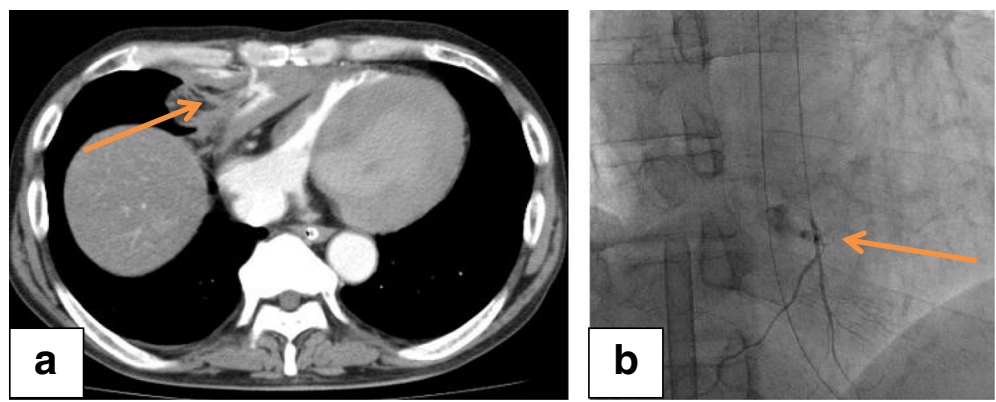

Fig. 5 Computed tomography and angiography findings from Patient 5. a Contrast-enhanced computed tomography from before the coronary angiography revealed right rib fractures, a sternum fracture, and a hematoma at the mediastinum with contrast extravasation (arrow). b Angiography after the coronary angiography revealed contrast extravasation at the right internal mammary artery (arrow) 


\section{Discussion}

We retrospectively identified five cases of CPR-related IMA injuries that were detected after VA-ECMO had been initiated (Tables 1, 2, and 3). These cases highlighted three important clinical principles. First, patients who have been resuscitated after cardiac arrest should undergo CT as soon as possible to identify any CPR-related injuries (especially IMA injuries), which can also help select the appropriate treatment(s). Second, TAE may be superior to thoracotomy for treating IMA injuries. Third, an initial 3000unit intravenous bolus of heparin may be redundant in cases that involve ECPR.

A retrospective study of $\mathrm{CT}$-detected CPR-related injuries revealed that $10 \%$ of cases involved chest wall hematomas, while $15 \%$ involved secondary signs of sternal fracture (retrosternal or mediastinal hematomas) [2]. In addition, a prospective study revealed that the incidence of CT-detected hemothorax was $11.3 \%$ [3]. Thus, CPR-related bleeding is not a rare complication, although the bleeding sources and their frequencies remain unclear. For example, bleeding can be caused by venous hemorrhage due to rib or sternal fracture [4] and/or arterial and branch hemorrhage due to ICA or IMA injuries. Although the 2015 CPR guidelines recommend targeting a reduced minimum compression depth $(5 \mathrm{~cm})$ [10], chest injuries have not been eliminated. On the other hand, the 2015 American Heart Association CPR guidelines recommend considering ECPR during a limited period of mechanical cardiorespiratory support for select patients with cardiac arrest and a suspected reversible etiology [11], as this approach may improve neurological outcomes [12]. While there are not many reports of CPR-related chest bleeding complications after ECPR [9], life-threatening chest bleeding complications may become increasingly common because of the new guideline recommendations.
IMA injuries can result in potentially life-threatening hemorrhage within a few minutes because of the rapid blood flow $(150 \mathrm{~mL} /$ minute) $[13,14]$. However, the patient described in Case 2 exemplifies the fact that chest radiography may not reveal indirect signs of IMA injuries (for example, slight hemothorax or a mediastinal hematoma) [13, 15], and early CT is required to identify active IMA bleeding and guide rapid surgical or angiographic intervention $[15,16]$. Cases 3 to 5 involved TAE treatment within 6 hours after the cardiac arrest, and the successful resuscitations and treatments in Cases 4 and 5 were based on the early CT findings. Unfortunately, patient 3 died because of hemorrhagic shock, as early intervention was unsuccessful because of arterial spasm. Of interest, IMA bleeding can result in temporary hemostasis because of arterial spasm and hypotension, which can lead to delayed bleeding after these complications are treated [13, 14, 17]. The deaths of patients 1 and 2 were caused by hemorrhage shock because of the delayed treatment. The TAE in patient 1 was performed $>9$ hours after the cardiac arrest because contrast extravasation was not detected during the first CT. In patient 2, the thoracotomy was performed at $>48$ hours after the cardiac arrest because he did not undergo $\mathrm{CT}$ at his admission and exhibited stable $\mathrm{Hb}$ levels during a 6-hour period. Therefore, if the initial CT reveals massive hemorrhage, angiography should be considered to temporarily achieve hemostasis and delay bleeding. Furthermore, TAE may be performed aggressively in cases with IMA injuries, even if no active extravasation is detected during angiography [17].

Early contrast-enhanced CT should be performed to identify any CPR-related injuries and their etiologies, which can determine the indication for early TAE or thoracotomy. The selection of TAE or thoracotomy remains controversial, although surgery may be the first choice if the patient's condition does not permit

Table 1 Patient characteristics

\begin{tabular}{|c|c|c|c|c|c|c|c|c|}
\hline Case & $\begin{array}{l}\text { Age } \\
\text { (years) }\end{array}$ & Sex & Initial rhythm & ECPR & $\begin{array}{l}\text { Time from CPR } \\
\text { to VA-ECMO } \\
\text { (minutes) }\end{array}$ & Diagnosis & Past medical history & Oral medicine \\
\hline 1 & 65 & Male & VF? & Yes & 45 & AMI & $\mathrm{AF}, \mathrm{AMI}, \mathrm{DM}, \mathrm{HT}, \mathrm{HL}$ & $\begin{array}{l}\text { Aspirin, clopidogrel, } \\
\text { warfarin }\end{array}$ \\
\hline 2 & 68 & Male & VF & No & 1857 & AMI & HT & N.p. \\
\hline 3 & 56 & Male & VF & Yes & 28 & AMI & $\begin{array}{l}\text { HT, type A aortic } \\
\text { dissection }\end{array}$ & Aspirin \\
\hline 4 & 62 & Male & PEA & Yes & 55 & AMl & N.p. & N.p. \\
\hline 5 & 62 & Male & VF & Yes & 40 & $\begin{array}{l}\text { Electrolyte } \\
\text { abnormality }\end{array}$ & N.p. & N.p. \\
\hline
\end{tabular}

$A F$ atrial fibrillation, $A M I$ acute myocardial infarction, $C P R$ cardiopulmonary resuscitation, $D M$ diabetes mellitus, $E C P R$ extracorporeal cardiopulmonary resuscitation, $H L$ hyperlipidemia, HT hypertension, N.p. nothing particular, PEA pulseless electrical activity, VA-ECMO venoarterial extracorporeal membrane oxygenation, 
Table 2 Patient clinical outcome

\begin{tabular}{|c|c|c|c|c|c|c|}
\hline Case & Extravasation in first $\mathrm{CT}$ & Location of bleeding & Intervention & $\begin{array}{l}\text { Intervention time } \\
\text { from cardiac arrest } \\
\text { (minutes) }\end{array}$ & $\begin{array}{l}\text { Death from } \\
\text { intervention } \\
\text { (minutes) }\end{array}$ & $\begin{array}{l}\text { Survival to } \\
\text { discharge }\end{array}$ \\
\hline 1 & No & Rt. ICA/Rt. IMA & TAE & 560 & 143 & Died \\
\hline 2 & Yes & Lt. IMA & Operation $\rightarrow$ TAE & 2908 & 367 & Died \\
\hline 3 & Yes & Lt. IMA & TAE & 313 & 41 & Died \\
\hline 4 & Yes & Bi. IMA & TAE & 327 & NA & $\mathrm{CPC} 3$ \\
\hline 5 & Yes & Rt. IMA & TAE & 181 & NA & $\mathrm{CPC} 3$ \\
\hline
\end{tabular}

Bi. bilateral, CPC cerebral performance category, CT computed tomography, ICA intercostal artery, IMA internal mammary artery, Lt. left, NA not applicable, Rt. right, TAE transcatheter arterial embolization

angiography [13]. Furthermore "damage control interventional radiography" uses a time-sensitive algorithm that prioritizes saving the life of a hemorrhaging patient, and may be performed for hemodynamically unstable patients after a traumatic injury [18]. A previous study revealed success rates of $91.6 \%$ for the patients in an embolization group and $66 \%$ for those in a surgically managed group [14]. The death of patient 2 may have been caused by surgical invasion and bleedings associated with the procedures combined with the concomitant intravenously administered anticoagulant treatment (unfractionated heparin) under VA-ECMO. Thus, TAE may be superior to thoracotomy because it is less invasive, causes less bleeding, and selectively stops arterial bleeding earlier than surgery (for example, in patients 4 and 5). Hence, we recommend that TAE be considered before surgery in cases that involve VA-ECMO, although exceptions may be made for patients in whom a massive hematoma compresses the right atrium or superior vena cava (such as in patient 3). In these circumstances, surgical treatment may be required to remove the hematoma and facilitate VA-ECMO blood flow.

The activated partial thromboplastin time before the surgery or TAE was excessively prolonged in all cases except for patient 4. Thus, if CT reveals CPR-related injuries but no interventions are planned, delayed bleeding may develop in association with arterial spasm and hypotension. In such cases, it may be useful to normalize the patient's coagulation status and perform careful systemic heparinization after starting VA-ECMO. The guidelines for extracorporeal life support recommend a heparin bolus (50 to 100 units $/ \mathrm{kg}$ ) at the time of cannulation [7], although this recommendation is not specific to ECPR. Furthermore, a retrospective study of VAECMO in patients with severe trauma with hemorrhagic shock revealed that the mean duration of heparin-free ECMO was 5 days, and that the patients did not experience thromboembolic events or unexpected blood clot formation [19]. Therefore, initially heparin-free ECPR may be optimal for reducing bleeding complications, and heparin could be administered after confirming that hemostasis has been achieved using angiography or repeat CT [20].

\section{Conclusions}

Patients who are resuscitated after cardiac arrest should undergo contrast-enhanced $\mathrm{CT}$ as soon as possible to identify any CPR-related injuries, especially IMA injuries, and to determine the appropriate course of treatment. TAE may be superior to thoracotomy for treating IMA injuries, although a 3000-unit intravenous bolus of heparin may be redundant at the start of ECPR.

Table 3 Blood test before intervention started and transfusion until intervention finished

\begin{tabular}{lllllllll}
\hline Case & $\begin{array}{l}\mathrm{Hb} \\
(\mathrm{g} / \mathrm{dL})\end{array}$ & $\begin{array}{l}\text { Plt } \\
(104 / \mu \mathrm{L})\end{array}$ & $\begin{array}{l}\text { APTT } \\
(\text { seconds })\end{array}$ & $\begin{array}{l}\text { Fibrinogen } \\
(\mathrm{mg} / \mathrm{dL})\end{array}$ & $\begin{array}{l}\text { RBC } \\
(\mathrm{U})\end{array}$ & $\begin{array}{l}\text { FFP } \\
(\mathrm{U})\end{array}$ & $\begin{array}{l}\text { PC } \\
(\mathrm{U})\end{array}$ & $\begin{array}{l}\text { Cryoprecipitate } \\
(\mathrm{pack})\end{array}$ \\
\hline 1 & 8.4 & 18.5 & $>130$ & 126 & 26 & 16 & 0 & 3 \\
2 & 5.3 & 7.1 & $>130$ & 170 & 16 & 10 & 20 & 0 \\
3 & 6.7 & 8.4 & $>130$ & 124 & 12 & 10 & 10 & 0 \\
4 & 14.2 & 14.1 & 49.7 & 169 & 0 & 6 & 0 & 0 \\
5 & 10.1 & 7 & $>130$ & 115 & 0 & 0 & 0 & 0 \\
\hline
\end{tabular}

APTT activated partial thromboplastin time, FFP fresh frozen plasma, $H b$ hemoglobin, $P C$ platelet concentrate, $P / t$ platelet, $R B C$ red blood cell, $U$ Unit 


\section{Abbreviations}

CAG: Coronary angiography; CPR: Cardiopulmonary resuscitation; $\mathrm{CT}$ : Computed tomography; ECMO: Extracorporeal membrane oxygenation; ECPR: Extracorporeal cardiopulmonary resuscitation; EMS: Emergency medical service; Hb: Hemoglobin; IABP: Intra-aortic balloon pump; ICA: Intercostal artery; IMA: Internal mammary artery; NBCA: N-butyl cyanoacrylate; PCl: Percutaneous coronary intervention; ROSC: Return of spontaneous circulation; TAE: Transcatheter arterial embolization; VA-ECMO: Venoarterial extracorporeal membrane oxygenation; VF: Ventricular fibrillation

\section{Acknowledgements}

We thank Editage (https://www.editage.jp) for English language editing

\section{Funding}

The authors declare that they did not receive any specific grant from funding agencies in the public or private sectors.

\section{Availability of data and materials}

Not applicable.

\section{Authors' contributions}

TYa drafted the manuscript, edited the manuscript for important intellectual and scientific content, served as the principal author, edited the revised version, and approved the final draft. The other authors revised the manuscript for important intellectual and scientific content and have read and approved the final draft.

\section{Ethics approval and consent to participate}

The institutional review board of Tokyo Metropolitan Bokutoh Hospital approved this case report.

\section{Consent for publication}

Written informed consent was obtained from the patients for publication of this case report and any accompanying images. A copy of the written consent is available for review by the Editor-in-Chief of this journal.

\section{Competing interests}

The authors declare that they have no competing interests.

\section{Publisher's Note}

Springer Nature remains neutral with regard to jurisdictional claims in published maps and institutional affiliations.

\section{Author details}

${ }^{1}$ Tertiary Emergency Medical Center, Tokyo Metropolitan Bokutoh Hospital, 4-23-15 Kotobashi, Sumida-ku, Tokyo 130-8575, Japan. ²Department of Emergency and Critical Care Medicine, Jichi Medical University Saitama Medical Center, 1-847 Amanuma-cho, Omiya-ku, Saitama-shi, Saitama 330-8503, Japan

\section{Received: 4 August 2017 Accepted: 7 October 2017}

\section{Published online: 11 November 2017}

\section{References}

1. Berg RA, Hemphill R, Abella BS, Aufderheide TP, Cave DM, Hazinski MF, et al. Part 5: Adult basic life support: 2010 American Heart Association Guidelines for Cardiopulmonary Resuscitation and Emergency Cardiovascular Care. Circulation. 2010;122:S685-705

2. Kim EY, Yang HJ, Sung YM, Cho SH, Kim JH, Kim HS, et al. Multidetector CT findings of skeletal chest injuries secondary to cardiopulmonary resuscitation. Resuscitation. 2011;82:1285-8.

3. Kim MJ, Park YS, Kim SW, Yoon YS, Lee KR, Lim TH, et al. Chest injury following cardiopulmonary resuscitation: a prospective computed tomography evaluation. Resuscitation. 2013;84:361-4.

4. Hotta Y, Koizumi T, Kawanami J, Sakamoto A, Komiyama N, Nishimura S. Sternum fracture and haemorrhage after cardiopulmonary resuscitation. Resuscitation. 2007:74:401-2.

5. Oya S, Shinjo T, Fujii Y, Kamo J, Teruya H, Kinoshita H. CPR related thoracic injury: a comparison of CPR guidelines between 2005 and 2010. Acute Med Surg. 2016;3:351-5.
6. Rutty GN, Morgan B. Frequency and number of resuscitation related rib and sternum fractures are higher than generally considered. Resuscitation. 2015; 93:A1-2.

7. Extracorporeal Life Support Organization. ELSO anticoagulation guidelines. 2014. p. 1-17. https://www.elso.org/portals/0/files/elsoanticoagulationguideline82014-table-contents.pdf. Accessed 9 July 2017.

8. Weidman JL, Shook DC, Hilberath JN. Cardiac resuscitation and coagulation. Anesthesiology. 2014;120:1009-14.

9. Kawakami S, Noguchi T, Doi T, Tahara Y, Sanada Y, Fukuda T, et al. Internal mammary artery injury related to chest compressions in a patient with post-cardiac arrest syndrome. Intern Med. 2016:55:1299-303.

10. Kleinman ME, Brennan EE, Goldberger ZD, Swor RA, Terry M, Bobrow BJ et al. Part 5: Adult basic life support and cardiopulmonary resuscitation quality: 2015 American Heart Association Guidelines Update for Cardiopulmonary Resuscitation and Emergency Cardiovascular Care. Circulation. 2015;132:S414-35.

11. Link MS, Berkow LC, Kudenchuk PJ, Halperin HR, Hess EP, Moitra VK, et al. Part 7: Adult advanced cardiovascular life support: 2015 American Heart Association Guidelines Update for Cardiopulmonary Resuscitation and Emergency Cardiovascular Care. Circulation. 2015;132:S444-64.

12. Sakamoto T, Morimura N, Nagao K, Asai Y, Yokota H, Nara S, et al. Extracorporeal cardiopulmonary resuscitation versus conventional cardiopulmonary resuscitation in adults with out-of-hospital cardiac arrest: A prospective observational study. Resuscitation. 2014;85:762-8.

13. Nomori H, Ootsuka T, Horio H, Naruke T, Suemasu K. Bilateral internal thoracic artery injury induced by blunt trauma. Jpn J Thoracic Cardiovasc Surg. 2003;51:214-6.

14. Whigham Jr CJ, Fisher RG, Goodman CJ, Dodds CA, Trinh CC. Traumatic injury of the internal mammary artery: embolization versus surgical and nonoperative management. Emerg Radiol. 2002;9:201-7.

15. Braatz T, Mirvis SE, Killeen K, Lightman NI. CT diagnosis of internal mammary artery injury caused by blunt trauma. Clin Radiol. 2001;56:120-3.

16. Chen JM, LV J, Ma K, Yan J. Assessment of internal mammary artery injury after blunt chest trauma: a literature review. J Zhejiang Univ Sci B. 2014;15: 864-9.

17. Kwon OY, Chung SP, Yoo IS, Song CJ, Kim IB, Kim SW. Delayed presentation of internal mammary artery rupture after blunt chest trauma: characteristic CT and plain $x$ ray findings. Emerg Med J. 2005;22:664-5.

18. Matsumoto J, Lohman BD, Morimoto K, Ichinose $Y$, Hattori T, Taira Y. Damage control interventional radiography (DCIR) in prompt and rapid endovascular strategies in trauma occasions (PRESTO): A new paradigm. Diagn Interv Imaging. 2015;96:687-91.

19. Arlt M, Philipp A, Voelkel S, Rupprecht L, Mueller M, Graf BM, et al. Extracorporeal membrane oxygenation in severe trauma patients with bleeding shock. Resuscitation. 2010;81:804-9.

20. Murphy DA, Hockings LE, Andrews RK, Aubroc C, Gardiner EE, Pellegrino VA et al. Extracorporeal membrane oxygenation-hemostatic complications. Transfus Med Rev. 2015;29:90-101.

\section{Submit your next manuscript to BioMed Central and we will help you at every step:}

- We accept pre-submission inquiries

- Our selector tool helps you to find the most relevant journal

- We provide round the clock customer support

- Convenient online submission

- Thorough peer review

- Inclusion in PubMed and all major indexing services

- Maximum visibility for your research

Submit your manuscript at www.biomedcentral.com/submit
Biomed Central 